\title{
Prospecção de água subterrânea em ambiente cristalino para grandes empreendimentos imobiliários: $O$ caso do Residencial Vale das Rosas - Tucumã/PA
}

Allex Raiol Cardoso Medeiros*, Fabiano das Neves, Franklim Roberto - Geoprospecto - Soluções em Geofísica

Copyright 2014, SBGf - Sociedade Brasileira de Geofísica

Este texto foi preparado para a apresentação no VI Simpósio Brasileiro de Geofísica, Porto Alegre, 14 a 16 de outubro de 2014. Seu conteúdo foi revisado pelo Comitê Técnico do VI SimBGf, mas não necessariamente representa a opinião da SBGf ou de seus associados. É proibida a reprodução total ou parcial deste material para propósitos comerciais sem prévia autorização da SBGf.

\section{Resumo}

O presente trabalho apresenta um estudo geofísico através da caracterização geoelétrica dos materiais geológicos em subsuperfície, que tiveram como objetivo a verificação das possibilidades de captação de águas subterrâneas (em fratura) e a indicação de locais para perfuração de poço visando captação de água subterrânea, como suprimento as necessidades públicas do Residencial Vale das Rosas localizadas no município de Tucumã-PA.

\section{Introdução}

No Brasil com o crescimento do mercado imobiliário, e consequentemente, dos bairros planejados populares com investimento do governo federal, através do programa minha casa minha vida, tem-se a necessidade de abastecimento de água para estes empreendimentos para consumo humano e uso doméstico. Associado a este contexto existe a necessidade, do conhecimento geológico das camadas em subsuperfície, para perfuração de poços que tenha vazão suficiente para abastecer estes empreendimentos.

$\mathrm{Na}$ região sul do Pará, o contexto geológico é de embasamento cristalino, e que para perfuração de poços tem-se a necessidade de detectar as fraturas que contém água subterrânea. Em meio a este cenário, os métodos geofísicos de características não invasivas têm apresentado bons resultados em tais aplicações. Campanhas geofísicas vêm sendo bastante utilizadas em estudos geológicos, para localizar fraturas.

Dentro deste contexto, o presenta trabalho apresenta os resultados da aplicação de levantamentos geofísicos, por meio do método da eletrorresistividade (tomografia geoelétrica) para caracterização geolétrica das fraturas que contém água de um residencial localizada no município de Tucumã, Estado do Pará. Através do estudo geofísico fez-se a caracterização geoelétrica dos materiais geológicos em subsuperfície, que tiveram como objetivo a verificação das possibilidades de captação de águas subterrâneas e a indicação de locais para perfuração de poço visando captação de água subterrânea, como suprimento as necessidades públicas do residencial.

\section{Área de Estudo}

Tucumã é um município brasileiro do interior do estado do Pará. O município de Tucumã está localizado na Mesorregião do Sudeste Paraense e na Microrregião de
São Félix do Xingu, na região sul do estado, distando da capital cerca de $750 \mathrm{~km}$. A sede municipal fica às margens da Rodovia PA-279.

A extensão territorial do município de Tucumã, compreendendo $2.535,11 \mathrm{~km}^{2}$ está toda inserida na área do Programa Grande Carajás. A sua população durante a década de 1980, cresceu consideravelmente estimulada por vários fatores, tais como, condições agroclimáticas favoráveis, exploração de madeira e extração do ouro.

Segundo o IBGE/2012 o município tinha 34.956 habitantes, e em 2010 o seu PIB era de $305.967,83$ mil. Segundo o PNUD/2000 o IDH do município de 0,747, é médio e sua renda per capita em 2010 era de $R \$$ 9.092,35.

Tucumã forma com a cidade vizinha, Ourilândia do Norte, a única área conurbada do sudeste do Pará, ver figura 1.

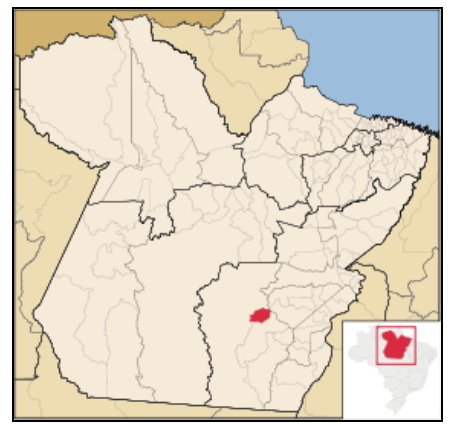

Figura 1 - Mapa de localização no Município de Tucumã/PA.

\section{Informações geológicas}

A região de Tucumã corresponde a um terreno granitogreenstone arqueano formado por rochas supracrustais de uma sequencia tipo greenstone belt (Grupo Tucumã) e por batólitos de granitoides (Granodiorito Rio Maria), truncado a norte pelo Cinturão Itacaúnas (Complexo Xingu, Suíte Plaquê e Grupo Sapucaia). No proterozóico, - granito-greenstone foi cortado por granitoides anorogênicos (Granito Seringa e Velho Guilherme) e o Cinturão Itacaúnas por corpos máfico-ultramáficos da Suíte Cateté (Macambira e Vale, 1997).

$\mathrm{Na}$ região de Tucumã, as unidades litológicas apresentam-se bastante deformadas, caracterizadas por dobramentos e milonitização principalmente imposta às metavulcânicas, as quais ocorrem em fatias dispostas lado a lado com mergulhos altos, condicionadas principalmente pelas zonas de cisalhamento de direção NW-SE.

O arcabouço estrutural granito-greenstone de Tucumã é caracterizado por um sistema de zonas de cisalhamento dúctil-rúptil oblíquas e transcorrentes, orientadas preferencialmente segundo NW-SE e E-W 
respectivamente, desenhando um mosaico entrelaçado e anostomótico (Costa et al, 1993). As zonas de cisalhamento oblíquas NW-SE são mais proeminentes e apresentam componentes de cavalgamento e direcional destral, mergulhando fortemente para NE e raramente para SW. As zonas de cisalhamento transcorrentes de direção E-W ocorrem no extremo norte do greenstone belt de Tucumã e a elas associam-se uma foliação milonítica e uma lineação de estiramento sub-horizontal.

Zonas de cisalhamento N-S, tanto rúpteis como dúcteis, e falhas normais NW-SE ocorrem localmente afetando as rochas supracrustais e os granitoides. Essa estruturação arqueada foi, em parte, modificada pela intrusão do Granito Velho Guilherme e por falhas transcorrentes NESW, relacionadas ao evento distensivo do Proterozóico, ver figura 2.

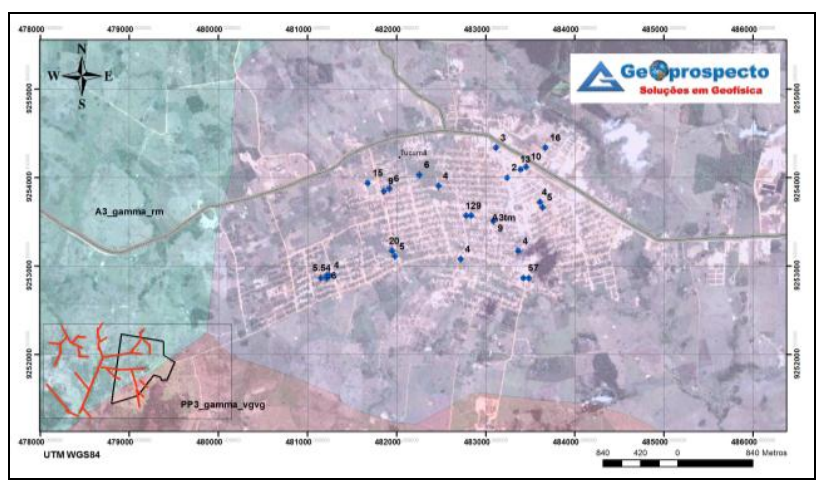

Figura 2 - Esboço geológico da região de Tucumã/Pará. $\mathrm{A}$ área do polígono refere-se às dependências do Residencial Vale das Rosas. Os lineamentos estão interpretados através das linhas vermelhas. Os pontos em azul correspondem aos poços cadastrados pelo sistema SIAGAS com os respectivos valores de vazão em $\mathrm{m}^{3} / \mathrm{h}$.

\section{Metodologia - Eletrorresistividade}

O método geofísico da eletrorresistividade baseia-se na determinação da resistividade aparente do substrato a partir da resposta ao fluxo de uma corrente elétrica (Ward, 1990). O principio básico do método consiste na aplicação de uma corrente elétrica artificial, contínua ou alternada, no solo por meio de um eletrodo localizado na superfície, com o objetivo de medir o potencial elétrico gerado nas proximidades do fluxo de corrente (usando um equipamento conhecido como eletrorresistivímetro). Utilizando um par de eletrodos de corrente (A-B) e um par de eletrodos de potencial (M-N), pode-se obter a diferença de potencial gerada, sendo possível associa-la à resistividade elétrica das rochas em subsuperfície e, posteriormente relacionar com variações.

Dentre os diversos tipos de arranjos de campo disponíveis para a técnica do caminhamento elétrico, o presente trabalho utiliza o arranjo dipolo-dipolo, devido à disposição dos eletrodos em arranjo simétrico, facilidade operacional durante a aquisição, baixa razão sinal/ruído, além de uma resolução lateral adequada aos objetivos do trabalho. Ver Figura 3.

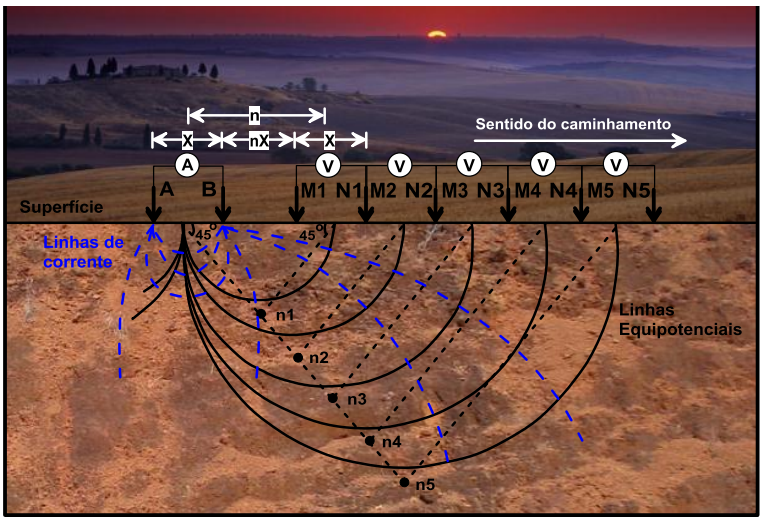

Figura 3 - Arranjo Dipolo-Dipolo - CE.

\section{Levantamento de campo}

Para iniciar o levantamento geofísico foram coletadas 04 linhas (perfil geofísico) com variação de comprimento entre $475 \mathrm{~m}$ e $500 \mathrm{~m}$; sendo que no decorrer de cada linha, a cada $25 \mathrm{~m}$ foi cravada uma estaca para fins de localização da linha. Para realização dessa tarefa, utilizou-se um receptor GPS Garmin Etrex, modelo Venture HC (precisão aproximada de $10 \mathrm{~m}$ ), cujas coordenadas geográficas foram em Universal Transversal de Mercator - UTM (datum WGS 84). As Linhas de geofísica foram locadas mediante 0 auxilio de 03 auxiliares de campo. Tal atividade teve por objetivo dimensionar os perfis a serem coletados e facilitar o posicionamento dos pontos promissores para perfuração.

A área do levantamento, já demonstrada no mapa da Figura 5, dista $3 \mathrm{~km}$ a oeste da sede da cidade de Tucumçã/PA. Os poços cadastrados pelo Sistema de Informação de Águas Subterrâneas (SIAGAS) da CPRM (Serviço Geológico do Brasil) possuem uma vazão média de $7,58 \mathrm{~m}^{3} / \mathrm{h}$, sendo a máxima de $20 \mathrm{~m}^{3} / \mathrm{h}$ e a mínima 2 $\mathrm{m}^{3} / \mathrm{h}$; e profundidade média de 108 metros, sendo a máxima de $200 \mathrm{~m}$ e a mínima de $40 \mathrm{~m}$.

O levantamento geofísico foi realizado utilizando um Resistivímetro Auto Energia, modelo ERMS 2011. Foram utilizados eletrodos de aço inox cobreado com $12,5 \mathrm{~mm}$ de diâmetro e $50 \mathrm{~cm}$ de comprimento. A conexão entre os eletrodos e o equipamento foi realizada por 04 carretéis com $300 \mathrm{~m}$ de fio cada, e uma isolação de 1000 V.

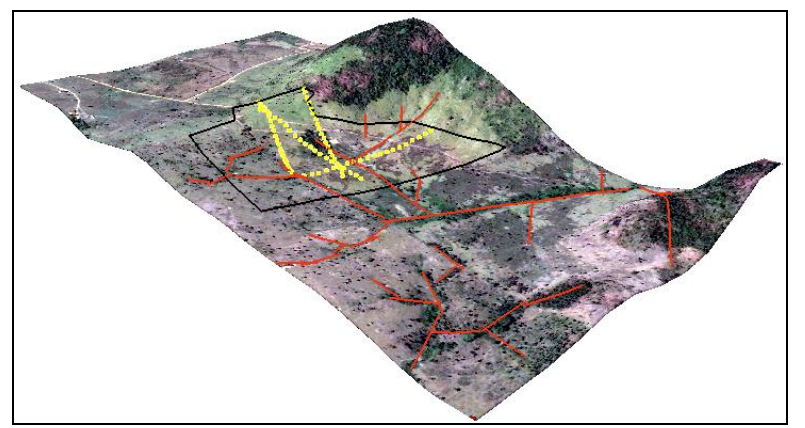

Figura 5 - Mapa das Linhas de caminhamento elétrico coletados com elevação e lineamentos no Residencial Vale das Rosas - Tucumã - Pará. 


\section{Inversão, Resultados e Interpretação}

A inversão dos dados de caminhamento elétrico ( $L$ 01, L 02, L 03 e L 04) se deu por suavização, também conhecida por "smooth inversion" que utiliza algoritmos baseados em um esquema de células. A inversão foi efetuada sem que o usuário entre com um modelo geológico inicial construído, desta forma, um processo automático de imageamento. O programa utilizado neste projeto é o RES2DINV que possibilitou a determinação de um modelo geoelétrico invertido.

De acordo com os resultados obtidos observou-se que a linhas L01, 02, 03 e 04 (ver figura 6 a 9) apresentaram indícios de possíveis presenças de estruturas armazenadoras de água subterrânea, ou seja, indícios de fraturas.

No perfil L01 foram identificadas fraturas com material pouco resistivo (cor azul), provavelmente saturado de água infiltrada. A localização será entre a estaca L1_03 e 04 deste perfil (Ponto D), seguindo a coordenada UTM E: 479022 / UTM N: 9251887, na estaca L1_06 Ponto B1, coordenada UTM E: 479081 / UTM N: 9251862, Ponto A1 entre as estacas L1_09 e 10, seguindo a coordenada UTM E: 479160 / UTM N: 9251826, Ponto A2 entre as estacas L1_14 e 15, seguindo a coordenada UTM E: 479274 / UTM N: 9251776 e Ponto C1 entre as estacas L1_16 e 17, na coordenada UTM E: 479322 / UTM N: 9251755 (WGS84) conforme mostra figura 6 . As regiões de coloração verde, laranja, vermelha e roxa representa o material rochoso.

No perfil L02 foi identificada fratura de baixa resistividade (cor azul), provavelmente saturado de água, cuja localização será entre a estaca L2_10 e L2_11 (Ponto A3), o qual está localizado UTM E: 479244 / UTM N: 92511941, conforme mostra figura 7.

No perfil L03 foram identificadas fraturas de baixa resistividade (cor azul), localizad na estaca L3_06 (Ponto B2), entre L3_09 e 10 (Ponto C2) e entre L3_12 e 13 (Ponto A4) o qual está localizado, respectivamente, UTM E: 479020 / UTM N: 9251885, UTM E: 479015 / UTM N: 9251798 e UTM E: 479015 / UTM N: 9251722, conforme mostra Figura 8.

Por fim, no perfil L04 foram identificadas fraturas de baixa resistividade (cor azul), provavelmente saturado de água, cuja localização será entre L4_09 e 10 (Ponto C3) e entre L4_14 e 15 (Ponto A4) o qual está localizado, respectivamente, UTM E: 478985 / UTM N: 9251885 e UTM E: 479266 / UTM N: 9251883, conforme mostra Figura 9.

Os pontos A1, A2, A3, A4, B1, B2, C1, C2, C3, C4 e D estão sendo indicados em ordem de prioridade de perfuração.

\section{Conclusões}

Os resultados obtidos com os Caminhamentos Elétricos permitiram identificar os locais com maior probabilidade de sucesso para perfuração de poços para captação de água subterrânea do Residencial Vale das Rosas. Para isto, devem ser observadas as seguintes premissas:
$\mathrm{Na}$ área pesquisada foram identificados 11 possíveis pontos promissores para perfuração de poços para captação de água (ver Figura 10);

O perfil L01 na região de cor azul (fratura A1, A2, B1, C1 e D), uma zona menos resistiva, indicando possível presença de água na rocha fraturada. $A$ indicação $D$ coincide com o Ponto B2 do perfil 03;

No perfil L02 na região de cor azul (fratura A3), como zona menos resistiva, também indicando possível presença de água na rocha fraturada;

No perfil L03 na região de cor azul (fratura A4, B2 e C2), como zona menos resistiva, também indicando possível presença de água na rocha fraturada;

No perfil L03 na região de cor azul (fratura C3 e C4), como zona menos resistiva, também indicando possível presença de água na rocha fraturada;

As fraturas identificadas no levantamento geofísico encontram-se na camada de filito alterado, filito e quartzito;

\section{Agradecimentos}

Agradecemos a todos que participaram direto $\mathrm{e}$ indiretamente neste projeto.

\section{Referências}

COSTA, J. B. S.; MACAMBIRA, E. M. B.; VALE, A. G.; ARAUJO, O. J. B.; PINHEIRO, R. V. L.; JORGE JOÃO, $X$. da S. Evolução Litoestrutural da Região de São Félix do Xingu - Serra dos Carajás. São Paulo, 1993.

CORREIA JÚNIOR, Firmino Coutinho. Gênese do depósito aurífero do Cuca/Tucumã, com base nos fluidos hidrotermais e isótopos de chumbo. Tese de Mestrado. Universidade Federal do Pará. Belém, 2000.

Ward, S.H., 1990. Resistivity and Induced Polarization Methods. In: Ward, S. H. Editora: Geotechincal and Environmental Geophysics., SEG Special Publication. Vol.I. 


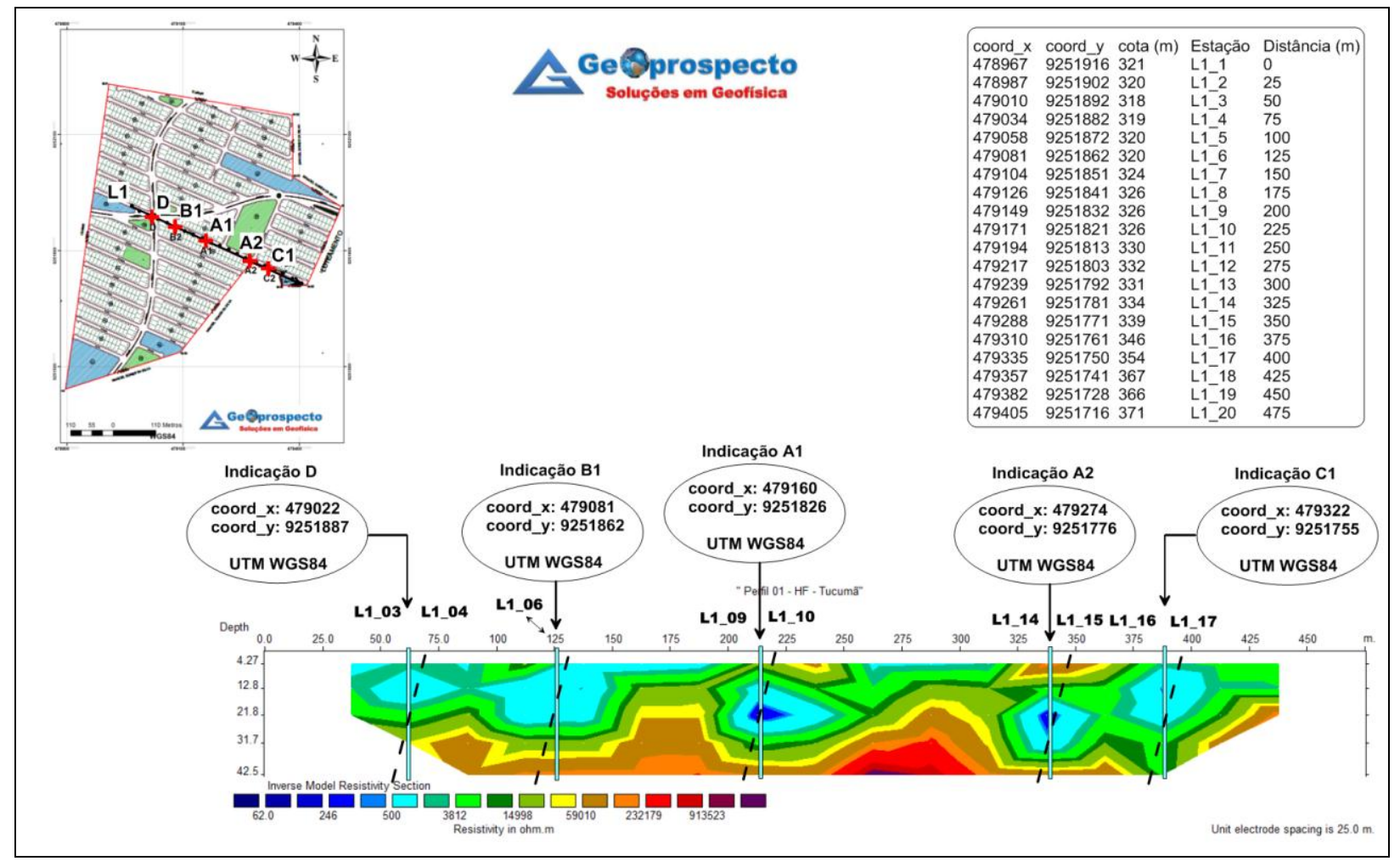

Figura 6 - Linha 01.

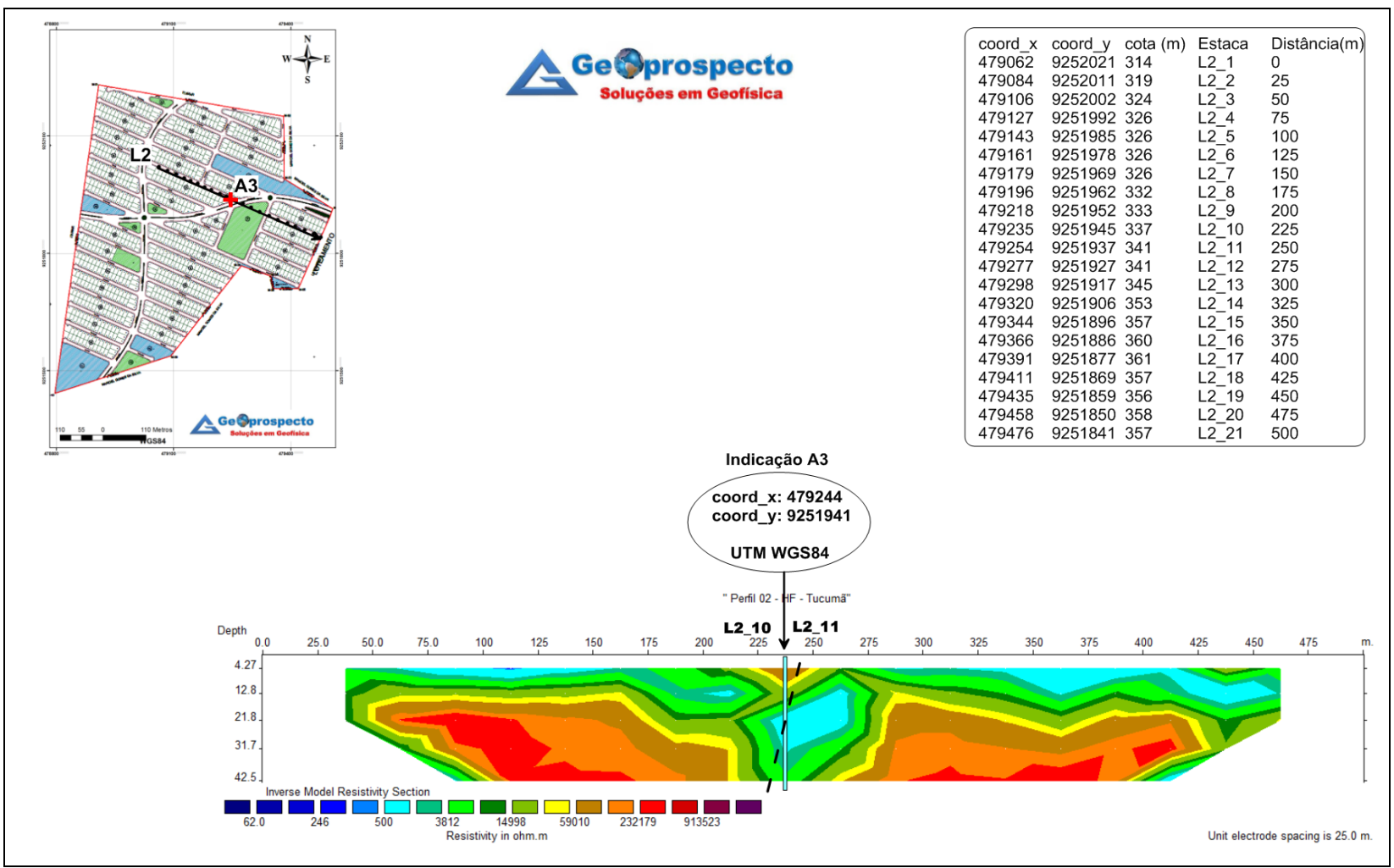

Figura 7 - Linha 02. 


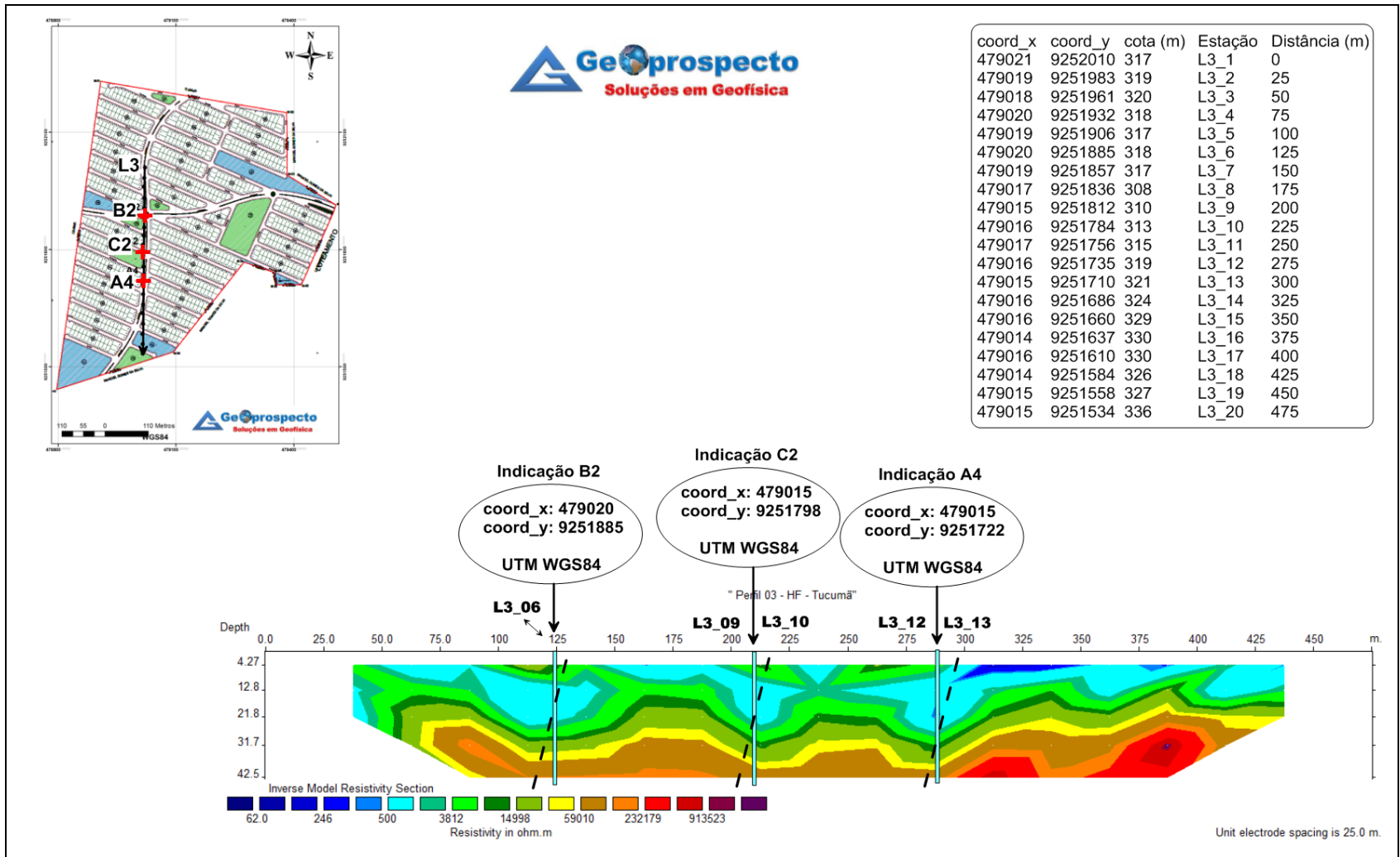

Figura 8 - Linha 03.

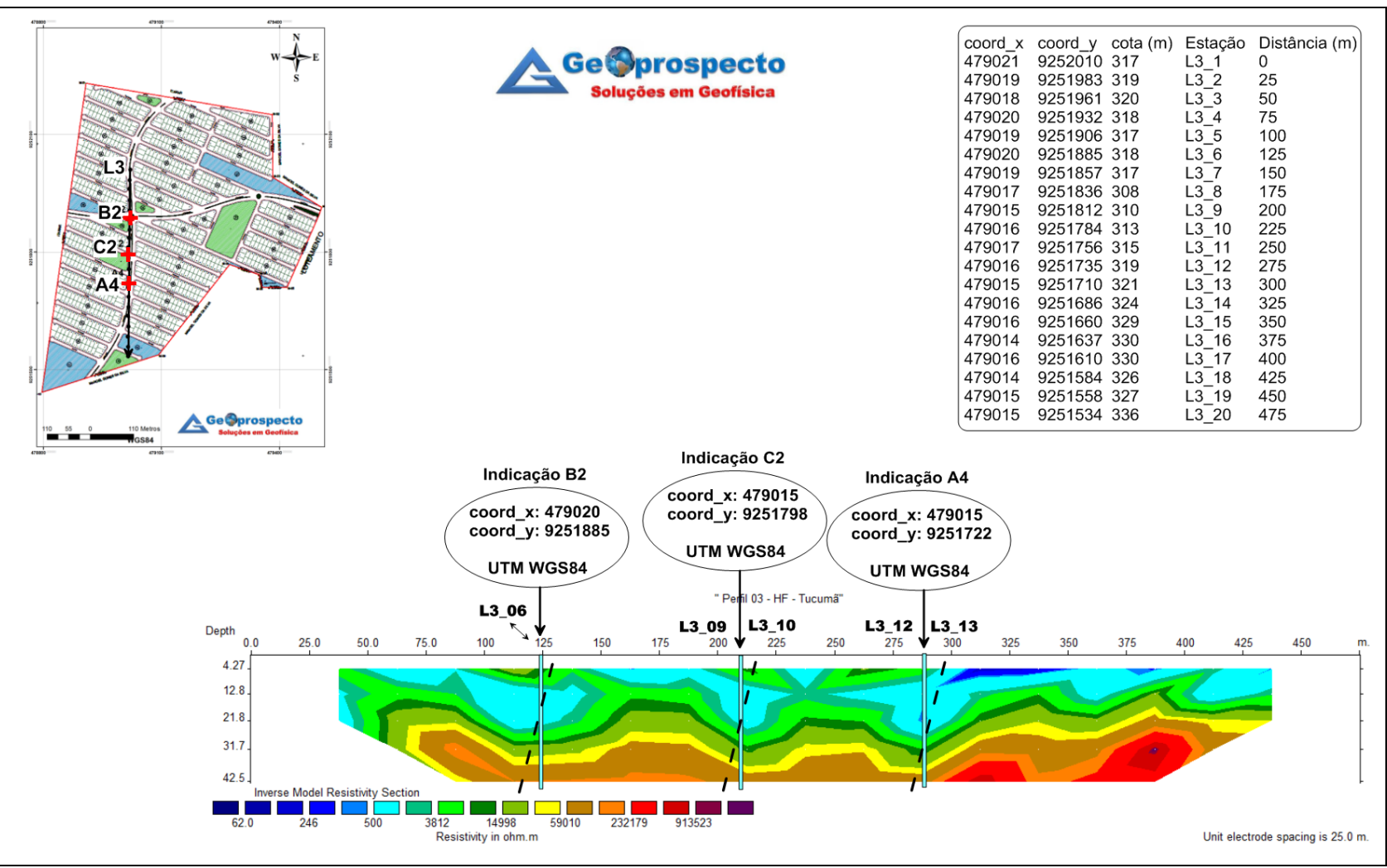

Figura 9 - Linha 04. 


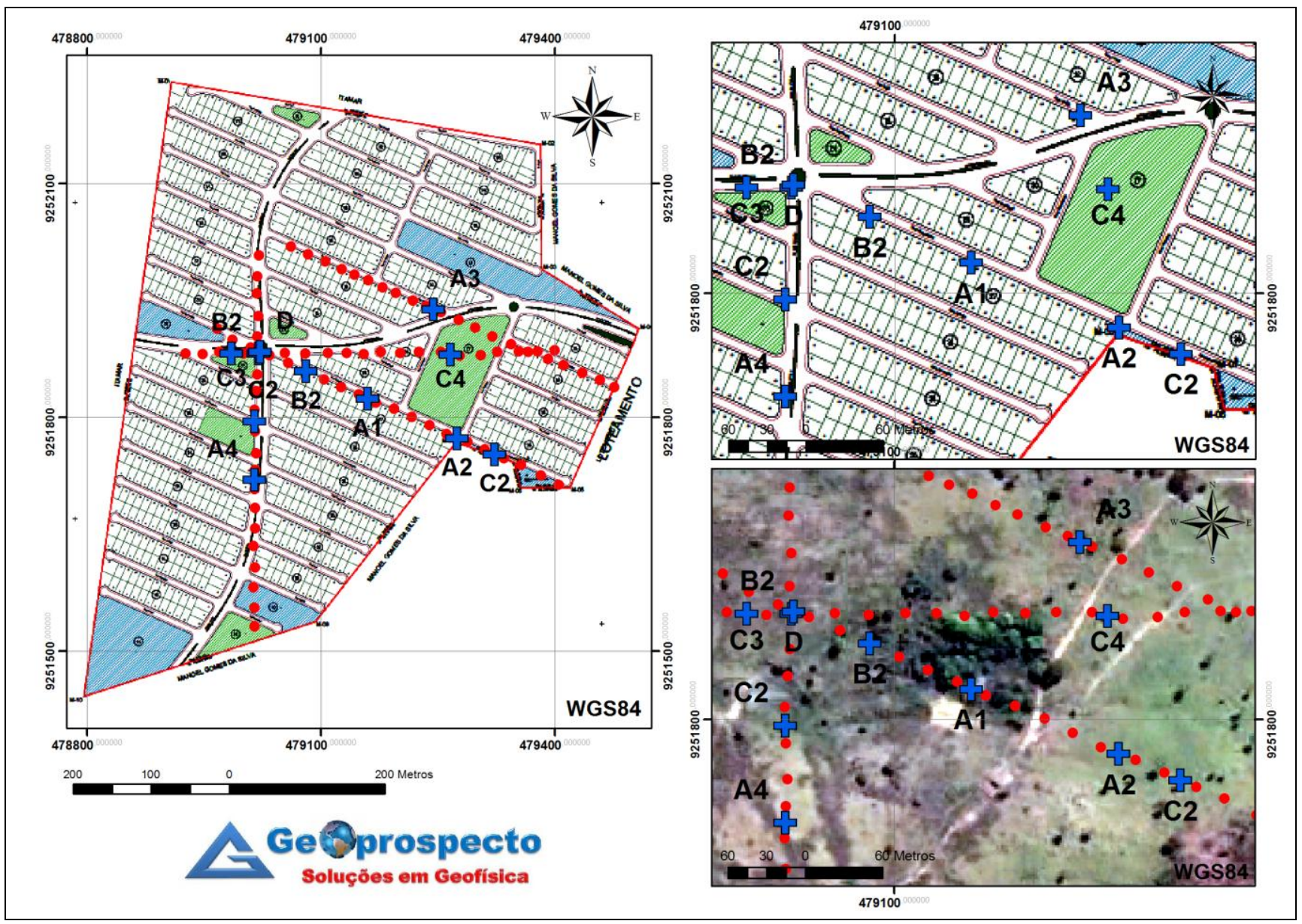

Figura 10 - Mapa do empreendimento com a posição dos pontos indicados com ampliação na área de interesse. 